\title{
RECUPERAÇÃO DE COBRE DE PLACAS DE CIRCUITO IMPRESSO ESGOTADAS A PARTIR DE EXTRAÇÃO SUPERCRÍTICA
}

\author{
C. O. CALGARO ${ }^{1}$, D. F. SCHLEMMER ${ }^{1}$, M. D. C. R. da SILVA $^{1}$, E. V. MAZIERO ${ }^{1}$, E. H. \\ TANABE $^{1}$ e D. A. BERTUOL ${ }^{1}$. \\ ${ }^{1}$ Universidade Federal de Santa Maria, Departamento de Engenharia Química \\ E-mail para contato: camila.itepjr@gmail.com
}

\begin{abstract}
RESUMO - O desenvolvimento da ciência e tecnologia propicia o crescimento da demanda por equipamentos elétricos e eletrônicos, que têm como componente primário as placas de circuito impresso (PCIs). Como esses equipamentos vêm se tornando obsoletos em um menor intervalo de tempo, as PCIs residuais tornam-se um problema de ordem global. As PCIs são compostas por cerâmicos, polímeros e metais, com destaque para o $\mathrm{Cu}$, metal presente em maior percentual. $\mathrm{O}$ que motiva o estudo da recuperação do $\mathrm{Cu}$ destes resíduos. Sendo o uso do $\mathrm{CO}_{2}$ supercrítico uma alternativa aos métodos convencionais. O estudo em questão compreendeu a separação das PCIs de celulares descartados, a moagem das PCIs em moinho de martelos e facas, a extração supercrítica com $\mathrm{CO}_{2}$ utilizando $\mathrm{H}_{2} \mathrm{O}_{2}$ e $\mathrm{H}_{2} \mathrm{SO}_{4}$ como cosolventes, e a lixiviação ácida. Com a extração supercrítica reduziu-se o tempo de lixiviação, pois em apenas 20 min. extraiu-se 48,5\% de $\mathrm{Cu}$, e com a lixiviação ácida convencional extraiu-se $45 \%$ de $\mathrm{Cu}$ em 3 h de reação.
\end{abstract}

\section{INTRODUÇÃO}

A produção de equipamentos elétricos e eletrônicos (EEE) é um dos setores da indústria de manufatura que mais cresce, incentivada pela inovação tecnológica e marketing intenso que estimulam a substituição rápida desses produtos. São gerados, mundialmente, de 20 a 50 milhões de toneladas de resíduos de EEE, o que representa um problema de ordem global (Lee et al., 2010; Huang et al., 2009).

As placas de circuito impresso (PCIs) são os componentes fundamentais dos EEE e motivam sua reciclagem, devido não somente ao apelo ambiental, mas à motivação econômica, por serem compostas por uma quantidade significativa de metais (Veit et al., 2006). A pureza dos metais preciosos contidos nas PCIs descartadas supera em 10 vezes a quantidade contida nos minerais mais ricos, por isso são chamadas de "recursos minerais urbanos" (Huang et al., 2009). Segundo Yamane et al. (2011), PCIs de celulares contém aproximadamente $63 \%$ de metais, $24 \%$ de cerâmicos e $13 \%$ de polímeros, composição esta que varia de acordo com o modelo e idade dos celulares. Os metais típicos presentes em PCIs são: cobre (20\%), ferro (8\%), estanho (4\%), níquel (2\%), chumbo (2\%), zinco $(1 \%)$, prata $(0,2 \%)$, ouro $(0,1 \%)$ e paládio $(0,005 \%)$ (Huang et al., 2009$)$. 


\section{9 a 22 de outubro de 2014 \\ Florianópolis/SC}

O tratamento adequado das placas de circuito impresso além de vantajoso se faz necessário, principalmente, pela quantidade de substâncias tóxicas presentes em sua composição, como os retardantes de chama, plásticos e metais pesados, que podem causar sérios problemas ambientais e até mesmo danos à saúde humana se não dispostas corretamente (Huang et al., 2009).

Contudo, a reciclagem das PCIs ainda é limitada devido à heterogeneidade dos materiais constituintes e à complexidade de sua produção. Por isso, vem se estudando a reciclagem desses materiais por processamento mecânico, térmico e químico ou a combinação destes (Park et al., 2009). O processamento mecânico é usado como um pré-tratamento para os processos hidrometalúrgicos (Yang et al., 2011), nos quais são empregados, como lixiviantes, ácidos minerais e agentes oxidantes para recuperação dos metais (Behnamfard et al., 2013). Os fluidos supercríticos também vêm sendo considerados como uma alternativa aos métodos convencionais, devido as suas propriedades vantajosas de transferência de massa em relação aos demais solventes (Herrero et al., 2010). A utilização do dióxido de carbono $\left(\mathrm{CO}_{2}\right)$ vem sendo investigada, pois ele possui um ponto crítico relativamente baixo $\left(\mathrm{Tc}=31,1^{\circ} \mathrm{C}, \mathrm{Pc}=7,38 \mathrm{MPa}\right)$, é ambientalmente aceitável, pode ser reciclado e reutilizado e ainda ser modificado com cosolventes (Lin et al., 2014).

Além da necessidade da busca de métodos mais eficientes de reciclagem das PCIs devido à problemática já descrita, há o incentivo da Política Nacional de Resíduos Sólidos (PNRS), que foi instituída no Brasil em 2010 e estabelece a responsabilidade compartilhada entre o governo, indústria, comércio e consumidor final no gerenciamento e na gestão dos resíduos sólidos e institui a logística reversa (Lei 12.305, 2010). Desta forma esta nova política ambiental vai estimular à implantação de plantas industriais destinadas a reciclagem de resíduos tecnológicos. Diante deste contexto, o presente trabalho teve como objetivo desenvolver um método de recuperação sustentável do cobre $(\mathrm{Cu})$ das PCIs de celulares, através do estudo do emprego de $\mathrm{CO}_{2}$ supercrítico e comparação com o processo de lixiviação ácida convencional.

\section{MATERIAIS E MÉTODOS}

\subsection{Processamento Mecânico}

O processamento mecânico constitui a etapa de pré-tratamento das placas de circuito impresso, compreendendo a desmontagem manual dos celulares descartados, a moagem e a separação granulométrica. As placas de circuito impresso foram separadas por amostragem e cominuídas em um moinho de martelos com malha de $5 \mathrm{~mm}$ de abertura. Realizou-se uma análise granulométrica das partículas que passaram pela malha do equipamento juntamente com as que ficaram retidas em seu interior. As partículas que permaneceram com granulometria superior a $1 \mathrm{~mm}$ foram cominuídas novamente, mas em um moinho de facas (Rone, modelo N-150), com malha de $2 \mathrm{~mm}$ de abertura. Fez-se então, uma análise granulométrica final com as duas frações obtidas.

\subsection{Caracterização Química das Placas de Circuito Impresso}

A determinação da composição química da amostra cominuída foi realizada por Espectrometria de Fluorescência de Raios-X com Energia Dispersiva (Shimadzu, modelo EDX-720) à vácuo. 


\section{9 a 22 de outubro de 2014 \\ Florianópolis/SC}

$\mathrm{O} \mathrm{Cu}$ presente nas PCIs foi quantificado a partir da lixiviação com água régia $\left(\mathrm{HNO}_{3}\right.$ e $\mathrm{HCl}$ na proporção de 1:3), utilizando $5 \mathrm{~g}$ de amostra cominuída, obtidos por quarteamento. Utilizou-se a razão sólido:líquido de $1 \mathrm{~g}: 50 \mathrm{~mL}$, a temperatura de $90^{\circ} \mathrm{C}$ e tempos de lixiviação de 1,2 , 3 e 4 horas, sob agitação. Yamane et al. (2011) também utilizou água régia para quantificação dos metais existentes nas PCIs, mas em condições diferentes. As soluções lixiviadas foram separadas por filtração do material sólido e analisadas por Espectrometria de Absorção Atômica (Agilent Technologies, 200 Series AA). Para isso, estas foram diluídas até uma concentração máxima $10 \mathrm{mg} / \mathrm{L}$ e acidificadas até $\mathrm{pH} \leq 1,5$, garantindo-se assim que o $\mathrm{Cu}$ estivesse na forma solúvel (Welz e Spering, 1999). As diluições foram realizadas em duplicata e as análises em triplicata.

\subsection{Lixiviações Ácidas}

As lixiviações ácidas à pressão atmosférica e com $\mathrm{CO}_{2}$ supercrítico foram realizadas em condições operacionais semelhantes, visando a posterior comparação da eficiência de recuperação do $\mathrm{Cu}$ entre os dois métodos. Em ambos os métodos, o percentual mássico de $\mathrm{Cu}$ extraído foi determinado em relação ao percentual mássico de $\mathrm{Cu}$ lixiviado das amostras de placas cominuídas a partir da água régia, sendo este último considerado como valor total de $\mathrm{Cu}$ existente na amostra. $\mathrm{A}$ determinação da eficiência de recuperação é descrita pela Equação 1.

$$
\% \text { Másssico de Cu recuperado }=\frac{\text { Massa de Cu lixiviado } \times 100}{\text { Massa da amostra } \times \% \text { Cu lixiado com água régia }}
$$

Lixiviação à pressão atmosférica: As lixiviações foram realizadas com $5 \mathrm{~g}$ de amostra cominuída, obtidos por quarteamento. As amostras foram colocadas no interior de um balão de vidro conectado a um condensador sob aquecimento e agitação. Ácido sulfúrico $\left(\mathrm{H}_{2} \mathrm{SO}_{4}\right)$ com concentração de $2 \mathrm{M}$ e peróxido de hidrogênio $\left(\mathrm{H}_{2} \mathrm{O}_{2}\right)$ com concentração de $30 \%$ (v/v) foram utilizados como lixiviantes. Adicionados a uma razão solido:líquido de $1 \mathrm{~g}: 10 \mathrm{~mL}$, onde $15 \%$ do volume de solução foi de peróxido e os outros $85 \%$ do volume foi de ácido. As lixiviações foram realizadas a uma temperatura de $35^{\circ} \mathrm{C}$, nos tempos de $20,60,120,180$ e 240 minutos. Essa temperatura foi utilizada por ser levemente superior a temperatura mínima do estado supercrítico do $\mathrm{CO}_{2}\left(31,1^{\circ} \mathrm{C}\right)$. As soluções lixiviadas foram separadas das partículas sólidas a partir de filtração e o $\mathrm{Cu}$ presente foi determinado por Espectrometria de Absorção Atômica com Chama (F-AAS).

Lixiviação supercrítica: As lixiviações foram realizadas com a mesma massa e proporção de reagentes do que as lixiviações à pressão atmosférica. Os lixiviantes $\mathrm{H}_{2} \mathrm{SO}_{4}$ e o $\mathrm{H}_{2} \mathrm{O}_{2}$ atuaram como cosolventes, modificando o $\mathrm{CO}_{2}$. As reações foram realizadas a $35{ }^{\circ} \mathrm{C}$ e $7,5 \mathrm{MPa}$, condições levemente superiores a pressão e temperatura mínimas para $\mathrm{CO}_{2}$ se comportar como fluido supercrítico. As extrações supercríticas foram realizadas nos tempos de 5, 15, 20 e 60 minutos. As soluções lixiviadas foram separadas das partículas sólidas através da válvula de extração existente na saída do reator e de filtros de papel colocados em seu interior. $\mathrm{O} \mathrm{CO}_{2}$ foi separado da solução lixiviada por expansão e o Cu extraído foi então determinado por F-AAS.

O sistema utilizado nas extrações supercríticas é apresentado na Figura 1. Os filtros, as amostras e os cosolventes foram colocados, inicialmente, no reator de extração, que é constituído de aço inox 304 e revestido internamente com teflon. O reator é encamisado, permitindo assim o controle de 
temperatura a partir de um banho ultratermostático com circulador. Depois da válvula de extração, além do frasco coletor, há outro frasco conectado contendo uma solução de hidróxido de sódio para realizar a lavagem do $\mathrm{CO}_{2}$ que se separa da solução extraída. $\mathrm{O} \mathrm{CO}_{2}(99,5 \%$ da Air Liquide) é fornecido ao sistema já pressurizado e a pressão requerida é alcançada a partir de uma bomba de alta pressão do tipo seringa (Teledyne ISCO, modelo 500D ).

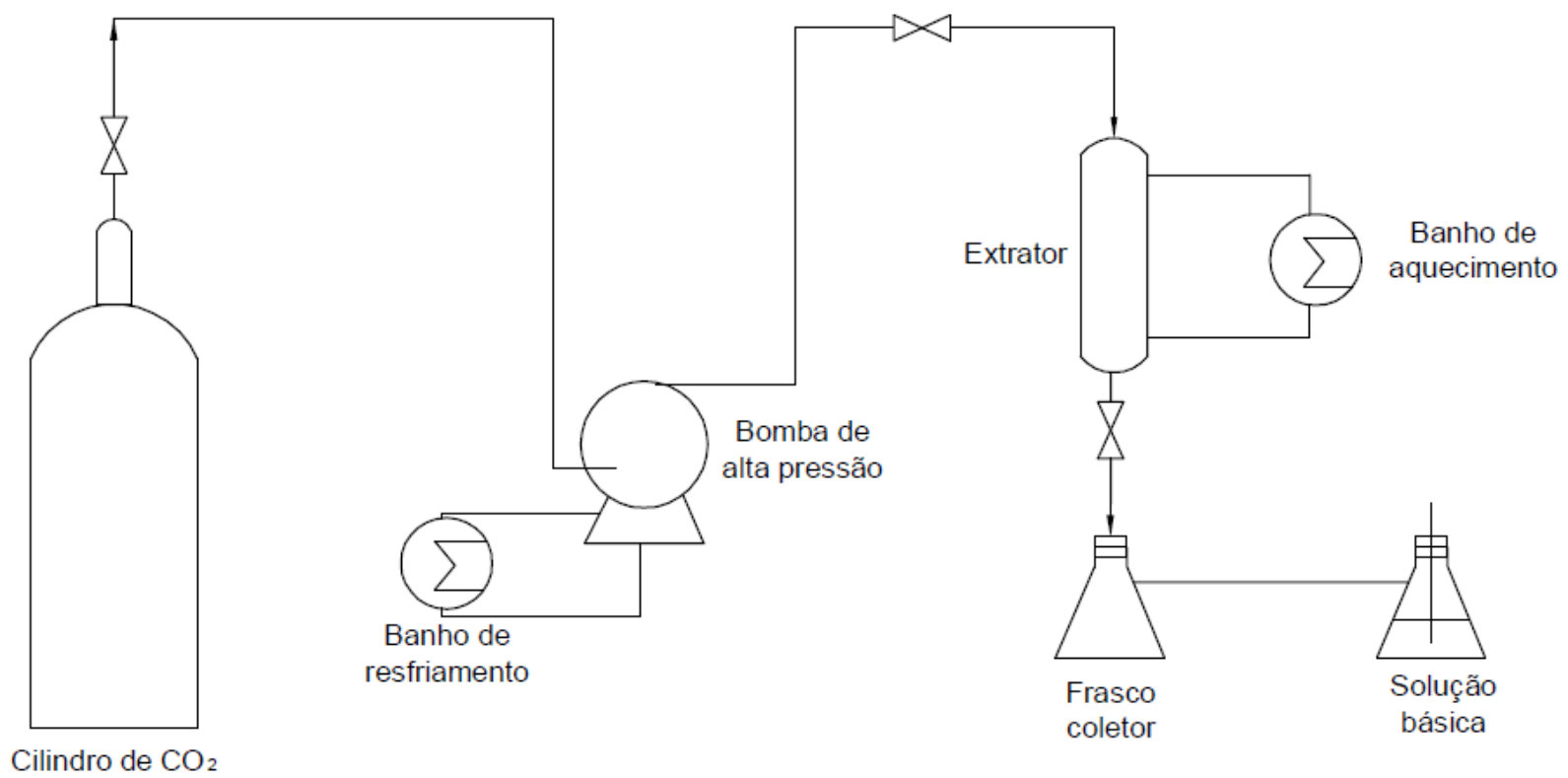

Figura 1 - Sistema de extração supercrítica.

\section{RESULTADOS E DISCUSSÕES}

\subsection{Processamento Mecânico}

Por amostragem, selecionaram-se 29 placas de circuito impresso de mesmo modelo, com peso médio de 14,32 g, totalizando 420,10 g, para passarem pelo processamento mecânico devido a sua maior representatividade. $O$ balanço de massa correspondente às moagens e separações granulométricas realizadas está apresentado na Figura 2.

A partir da Figura 2 pode-se inferir que através da moagem em moinho de martelos e de facas conseguiu-se reduzir significativamente o tamanho das placas de circuito impresso, do tamanho inicial de 8 x $4 \mathrm{~cm}$ para partículas com diâmetros inferiores a 1,7 mm em sua maioria. Sendo que, a moagem em moinho de facas também foi relevante para redução de tamanho, pois aproximadamente $88 \%$ da amostra total tornou-se menor que 1,7 mm. Enquanto que, usando-se apenas o moinho de martelos cerca de $32 \%$ da amostra total era maior que $1,7 \mathrm{~mm}$ e a distribuição granulométrica era mais ampla. 


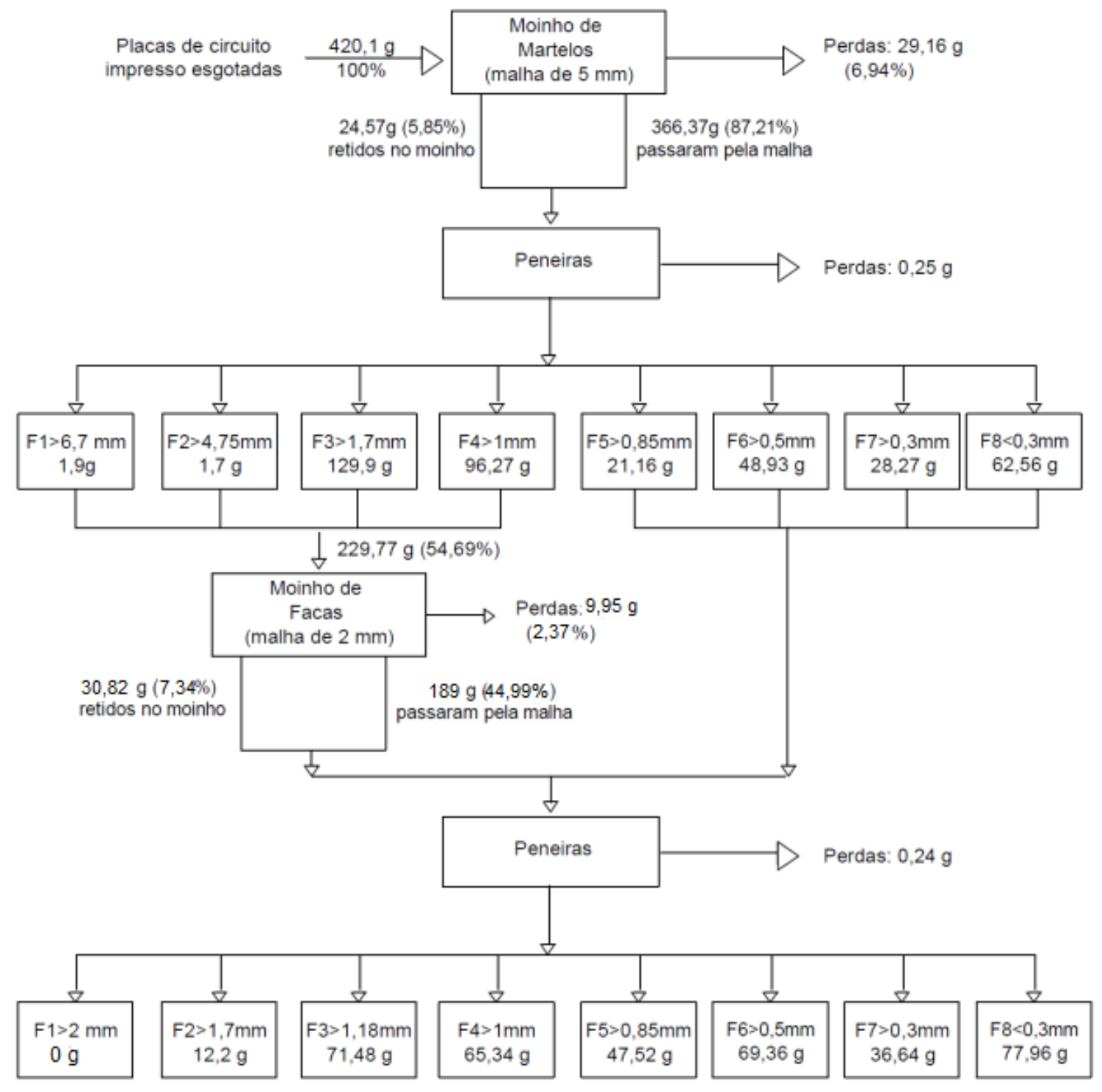

Figura 2 - Balanço de Massa do Processamento Mecânico das PCIs.

\subsection{Caracterização Química das Placas de Circuito Impresso}

A Tabela 1 apresenta a composição química das PCIs cominuídas, obtida por Espectrometria de Fluorescência de Raios-X com Energia Dispersiva (FRX). Onde se pode ver que o $\mathrm{Cu}$ é o metal presente em maior percentual mássico.

Tabela 1 - Composição química das placas de circuito impresso

\begin{tabular}{cccccccccccccc}
\hline $\begin{array}{c}\text { Componente } \\
\text { Percentual }\end{array}$ & $\mathrm{Cu}$ & $\mathrm{Si}$ & $\mathrm{Ca}$ & $\mathrm{Al}$ & $\mathrm{Ni}$ & $\mathrm{Ba}$ & $\mathrm{P}$ & $\mathrm{Fe}$ & $\mathrm{Sn}$ & $\mathrm{Ti}$ & $\mathrm{Zn}$ & $\mathrm{Ag}$ & Outros \\
$\begin{array}{c}\text { mássico (\%) } \\
31.95\end{array}$ & 23.08 & 17.43 & 11.11 & 2.71 & 2.46 & 2.41 & 1.94 & 1.78 & 1.59 & 1.19 & 0.34 & 2.01 \\
\hline
\end{tabular}


A Figura 3 descreve a quantificação do $\mathrm{Cu}$ presente nas PCIs, empregando água régia como lixiviante. Pela Figura 3, observa-se que a variação do tempo não influenciou no percentual de $\mathrm{Cu}$ lixiviado com água régia, já que este foi semelhante nos tempos de 1,2, 3 e 4 horas. O percentual mássico médio de $\mathrm{Cu}$ determinado a partir de lixiviação foi de 34,83\%, que se aproxima do valor obtido por FRX, de 31,95\%. Este valor é semelhante também ao determinado por Yamane et al. (2011), que foi de 34,5\% de $\mathrm{Cu}$ para PCIs de celulares. Assim, os 34,83\% de Cu resultante das lixiviações com água régia é considerado como a quantidade total de $\mathrm{Cu}$ existente nas PCIs de celulares estudadas.

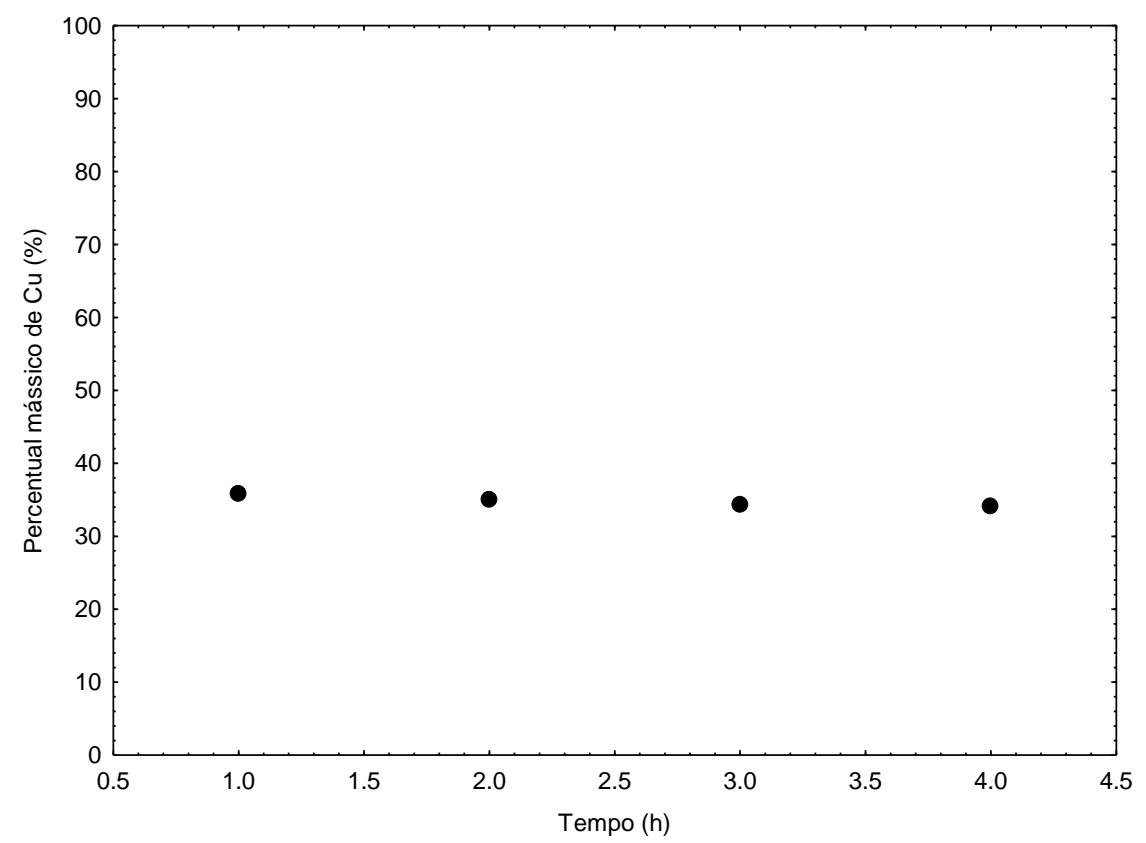

Figura 3 - Lixiviações com água régia para quantificação do $\mathrm{Cu}$ presente.

\subsection{Lixiviações Ácidas}

Nas lixiviações ácidas à pressão atmosférica conseguiu-se recuperar em torno de $45 \%$ em massa de $\mathrm{Cu}$ em 3 h e $46 \%$ em 4 h, de acordo com a Figura 4. Esses resultados demonstram que no tempo de 3 horas a reação tende ao equilíbrio, pois o aumento no percentual de extração não é mais significativo depois desse tempo. Isso também foi observado por Yang et al. (2011), que estudou a extração de $\mathrm{Cu}$ de PCIs de computadores pré-tratadas com ácido nítrico, e tem resultados demonstrando que tempos de lixiviação superiores a $3 \mathrm{~h}$ não aumentam significativamente a extração de $\mathrm{Cu}$.

Nas lixiviações ácidas com $\mathrm{CO}_{2}$ supercrítico recuperou-se $\mathrm{Cu}$ em percentual semelhante ao máximo obtido nas lixiviações ácidas à pressão atmosférica, mas em tempos de reação inferiores (Figuras 4 e 5). Lixiviou-se 51,7 \% de $\mathrm{Cu}$ em apenas $1 \mathrm{~h}$ de reação e 48,5\% em 20 min. de reação (Figura 5), podendo-se dizer que em 20 min. a reação de lixiviação já se aproxima do equilíbrio. 


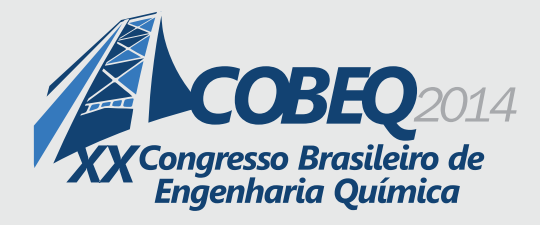

19 a 22 de outubro de 2014

Florianópolis/SC

Logo, com a lixiviação supercrítica se conseguiu reduzir o tempo reacional da lixiviação de $3 \mathrm{~h}$ para 20 min. Entretanto, como nas lixiviações executadas se extraiu somente $50 \%$ do $\mathrm{Cu}$ presente, é necessário otimizar as condições operacionais, como a razão sólido-líquido ou até mesmo avaliar a possibilidade de se realizarem múltiplos estágios de extração para ter uma maior eficiência.

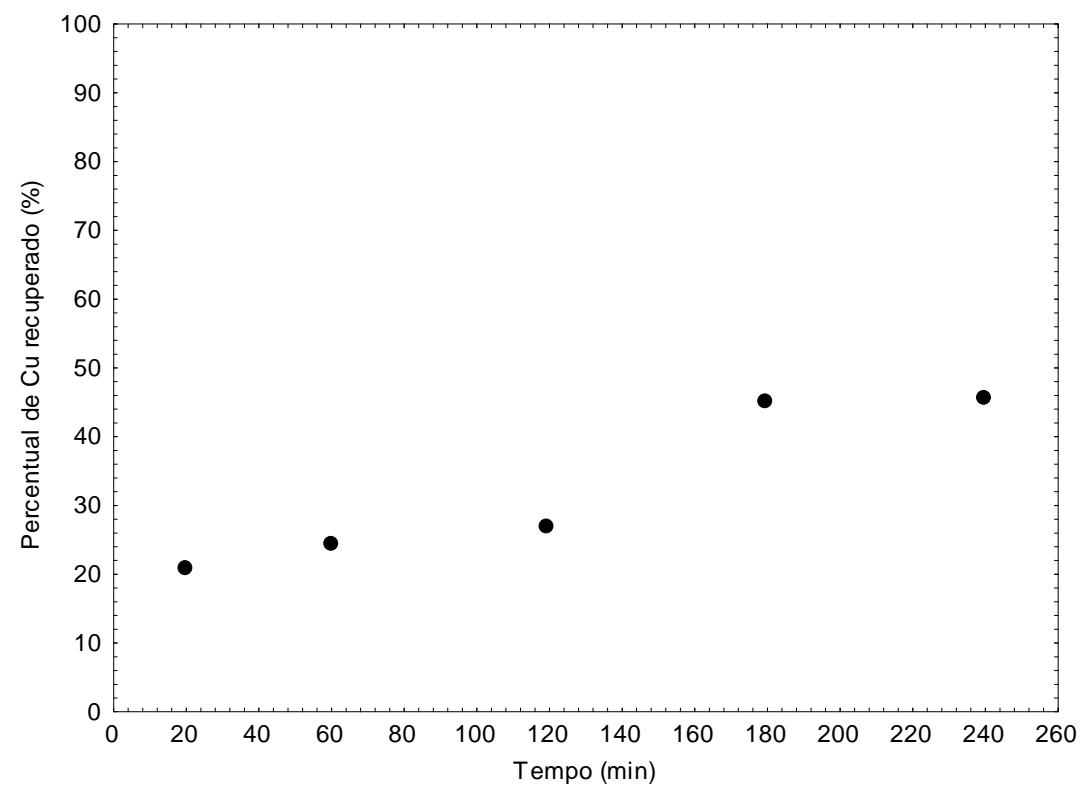

Figura 4 - Lixiviações ácidas à pressão atmosférica.

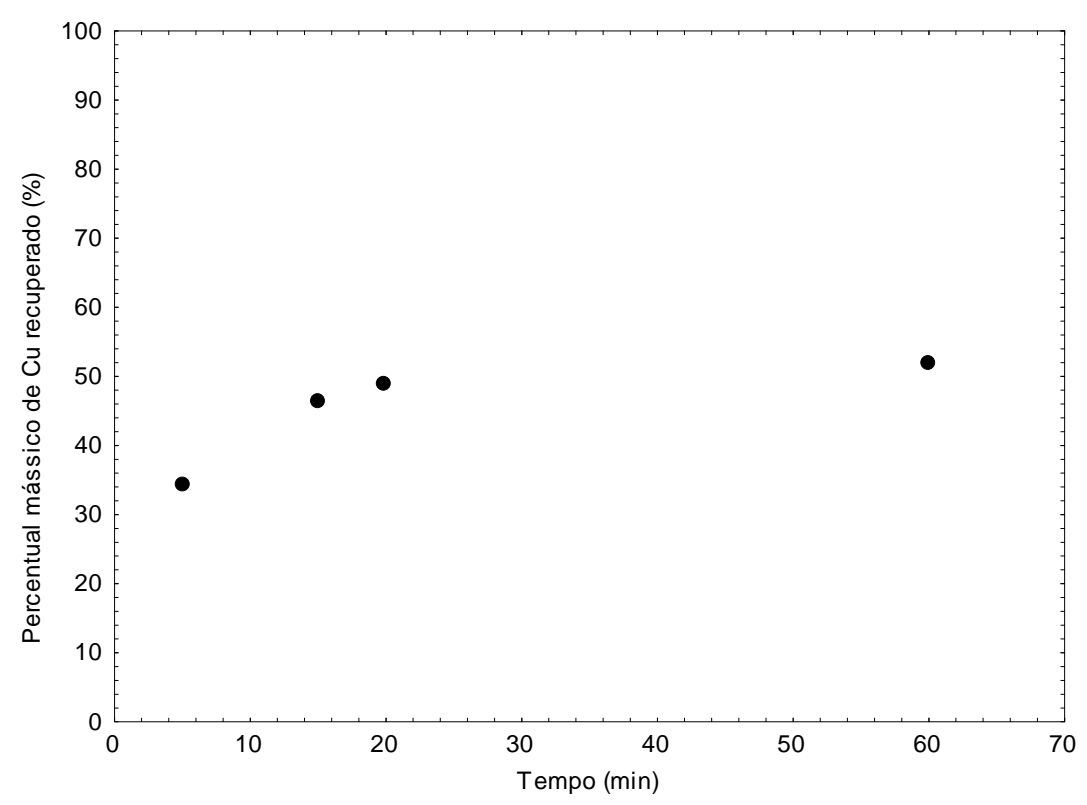

Figura 5 - Lixiviações ácidas com $\mathrm{CO}_{2}$ supercrítico. 


\section{9 a 22 de outubro de 2014 \\ Florianópolis/SC}

\section{CONCLUSÕES}

O processamento mecânico, compreendendo as duas moagens em moinho de martelos e de facas reduziu significativamente o tamanho das PCIs, pois $88 \%$ da amostra total foi reduzida de $8 \times 4$ cm para partículas com diâmetros inferiores a $1,7 \mathrm{~mm}$.

A caracterização química das PCIs a partir de FRX e lixiviações com água régia apresentou resultados próximos para a quantidade de $\mathrm{Cu}$ contido nas placas. Sendo o valor médio das lixiviações, de $34,83 \%$ adotado como referência, ou seja, como valor total de $\mathrm{Cu}$ presente nas PCIs. Com as lixiviações ácidas à pressão atmosférica se conseguiu recuperar cerca de $45 \%$ do total de Cu presente nas PCIs, em $3 \mathrm{~h}$ de reação. Já com as lixiviações empregando $\mathrm{CO}_{2}$ supercrítico recuperou-se 48,5\% do total de $\mathrm{Cu}$ existente, porém com apenas 20 min. de reação.

Portanto pode-se concluir que a lixiviação com $\mathrm{CO}_{2}$ supercrítico demonstrou um ganho de eficiência em termos de tempo em relação à lixiação ácida convencional, podendo ser uma alternativa promissora à reciclagem de PCIs e recuperação do $\mathrm{Cu}$ propriamente dita, mas carecendo ainda de estudos e de otimização das condições operacionais e das proporções dos reagentes.

\section{REFERENCIAS}

BEHNAMFARD, A.; SALARIRAD, M. M.; VEGLIO, F. Process Development for Recovery of Copper and Precious Metals from Waste Printed Circuit Boards with Emphasize on Palladium and Gold Leaching and Precipitation. Waste Manage., v. 33, p. 2354-2363, 2013.

BRASIL. Política Nacional de Resíduos Sólidos. Lei 12.305 de 2 de Agosto de 2010.

HERRERO, M.; MENDIOLA, J. A.; CIFUENTES, A.; IBÁÑEZ, E. Review: Supercritical fluid extraction: Recent advances and applications. J. Chromatogr. A, v. 1217, p. 2495-2511, 2010.

HUANG, K.; GUO, J.; XU, Z. Review - Recycling of waste printed circuit boards: A review of current technologies and treatment status in China. J. Hazard. Mater., v.164, p. 399-408, 2009.

LEE, C.; TANG, L.; POPURI, S. R. A study on the recycling of scrap integrated circuits by leaching. Waste Manage. Res., v. 29, p. 677-685, 2010.

LIN, F.; LIU, D.; MAITI, S.; PREMPEH, N.; HUA, Y.; LU, J. Recent Progress in Heavy Metal Extraction by Supercritical $\mathrm{CO}_{2}$ Fluids. Ind. Eng. Chem. Res., v. 53, p. 1866-1877, 2014.

PARK, Y.J.; FRAY, D.J. Recovery of high purity precious metals from printed circuit boards. $J$. Hazard. Mater., v. 164, p. 1152-1158, 2009.

VEIT, H. M.; BERNARDES, A. M.; FERREIRA, J. Z.; TENÓRIO, J. A. S.; MALFATTI, C. F. Recovery of copper from printed circuit boards scraps by mechanical processing and electrometallurgy. J. Hazard. Mater., v. B137, p.1704-1709, 2006.

YAMANE, L. H.; MORAES, V. T.; ESPINOSA, D. C. R.; TENÓRIO, J. A. S. Recycling of WEEE: Characterization of spent printed circuit boards from mobile phones and computers. Waste Manage., v.31, p.2553-2558, 2011.

YANG, H.; LIU, J.; YANG, J. Leaching Copper from Shredded Particles of Waste Printed Circuit Boards. J. Hazard. Mater., v. 187, p. 393-400, 2011.

WELZ, B. e SPERING, M. Atomic Absortion Spectrometry. WILEY-VCH: Third, Completely Revised Edition, 1999. p. 500-501. 